\title{
Construction Health and Safety: Effectiveness of Safety Incentive Programme
}

\author{
F.A. Zulkefli ${ }^{1}$, N. Md Ulang ${ }^{2, a}$, F. Baharum ${ }^{3}$ \\ ${ }^{1,2,3}$ School of Housing, Building and Planning, Universiti Sains Malaysia, 11800, Penang, Malaysia
}

\begin{abstract}
Safety incentive programmes or awards have become a standard practice for most construction companies as an effort to improve their safety performance on worksites. Providing incentives in the construction industry is an action which aims to motivate contractors and workers to achieve the objectives set by a project's management in order to improve overall performance on the project. This study was conducted to measure the effectiveness of such incentives and analyse the extent of involved parties' contribution to the success of the programme. It was found that workers have become motivated and site safety performance has also improved since the implementation of the safety incentive programme. Incentives are divided into two categories, (1) monetary and (2) non-monetary. These were evaluated based on workers' rate of achievement or behaviour.
\end{abstract}

\section{Introduction}

Construction safety performance is a vital factor that needs to be closely controlled on any construction project. A successful construction project not only depends on the quality of the building, the timeline or costs, but also on whether or not it achieves set safety performance goals. Nowadays, most construction project management teams realize the importance of construction safety and its implication towards the project. In order to reduce accidents, injuries and fatalities at construction sites, the Construction Industry Development Board, in collaboration with the Department of Occupational Health and Safety, put into place several initiatives to improve construction safety through a comprehensive Master Plan. According to statistics provided by the Department of Occupational Safety and Health, Malaysia, 69 cases of death and 83 cases of permanent disability were reported in the construction sector up until December 2013. These statistics were updated every 3 months by the DOSH. Meanwhile, construction accident statistics which were maintained for the period of 1993-2003 by SOCSO reported about 1,033 deaths out of 49,260 reported cases [1]. Several actions were taken by the responsible parties, especially from the Department of Occupational Safety and Health, to deal with these problems. One method was to introduce incentive programmes for employees in an effort to increase safety performances as well as to minimize accidents. Incentives in the construction industry are a concept that aims to motivate contractors to achieve building project goals which will, in effect, lead to better overall project performance [2]. The basic principle of safety incentives is to take advantage of contractors' desire to maximize their profit by giving them an opportunity to earn an even greater return if they manage to accomplish the contract efficiently. Safety incentives are also used to reduce the incidence of injury at construction sites $[3,4]$. Site safety itself is 
affected by four main factors: company safety policy, construction process, safe management of personnel and incentives [5].

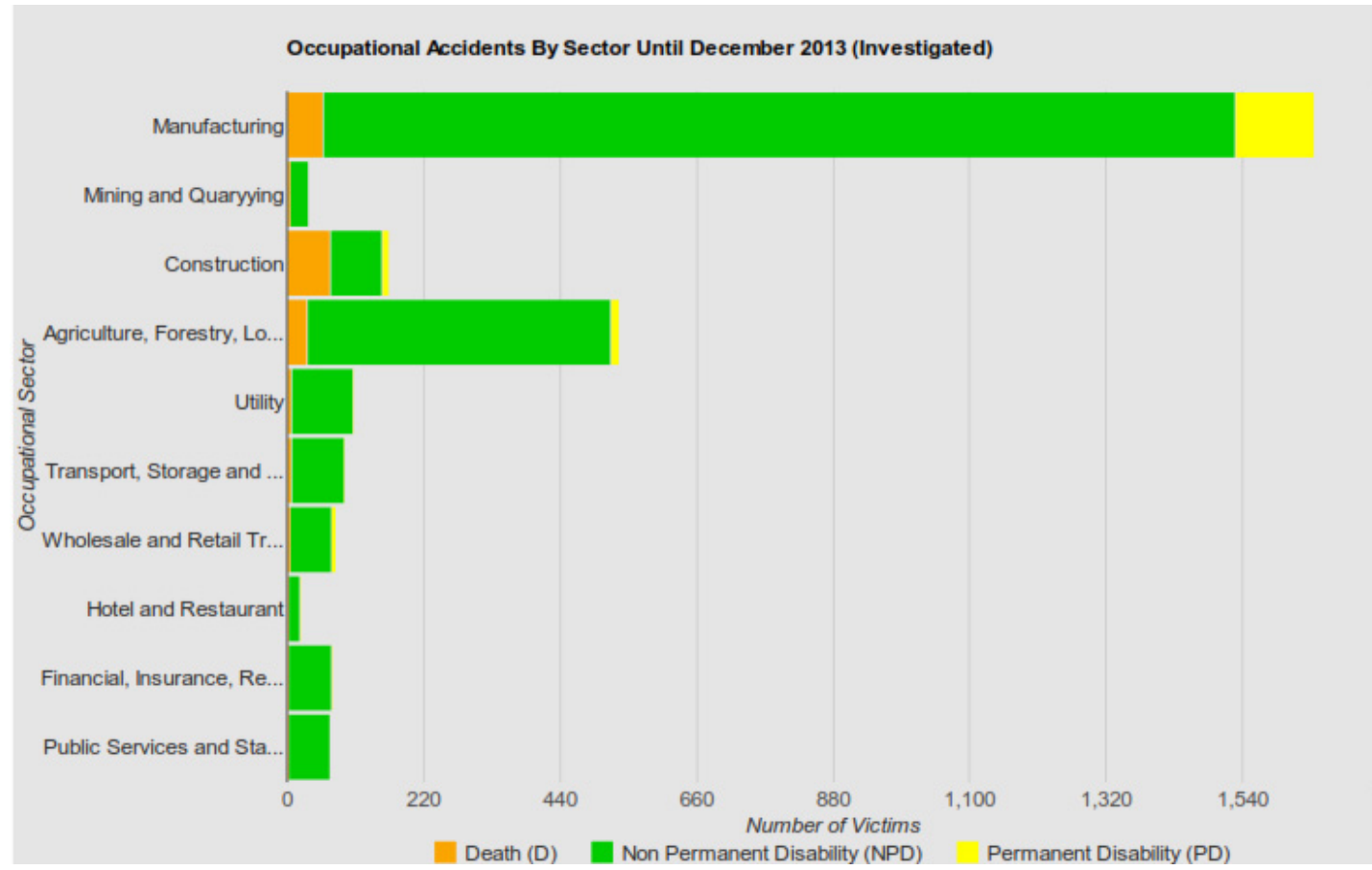

Figure 1: Occupational accidents by sector until 2013 [6]

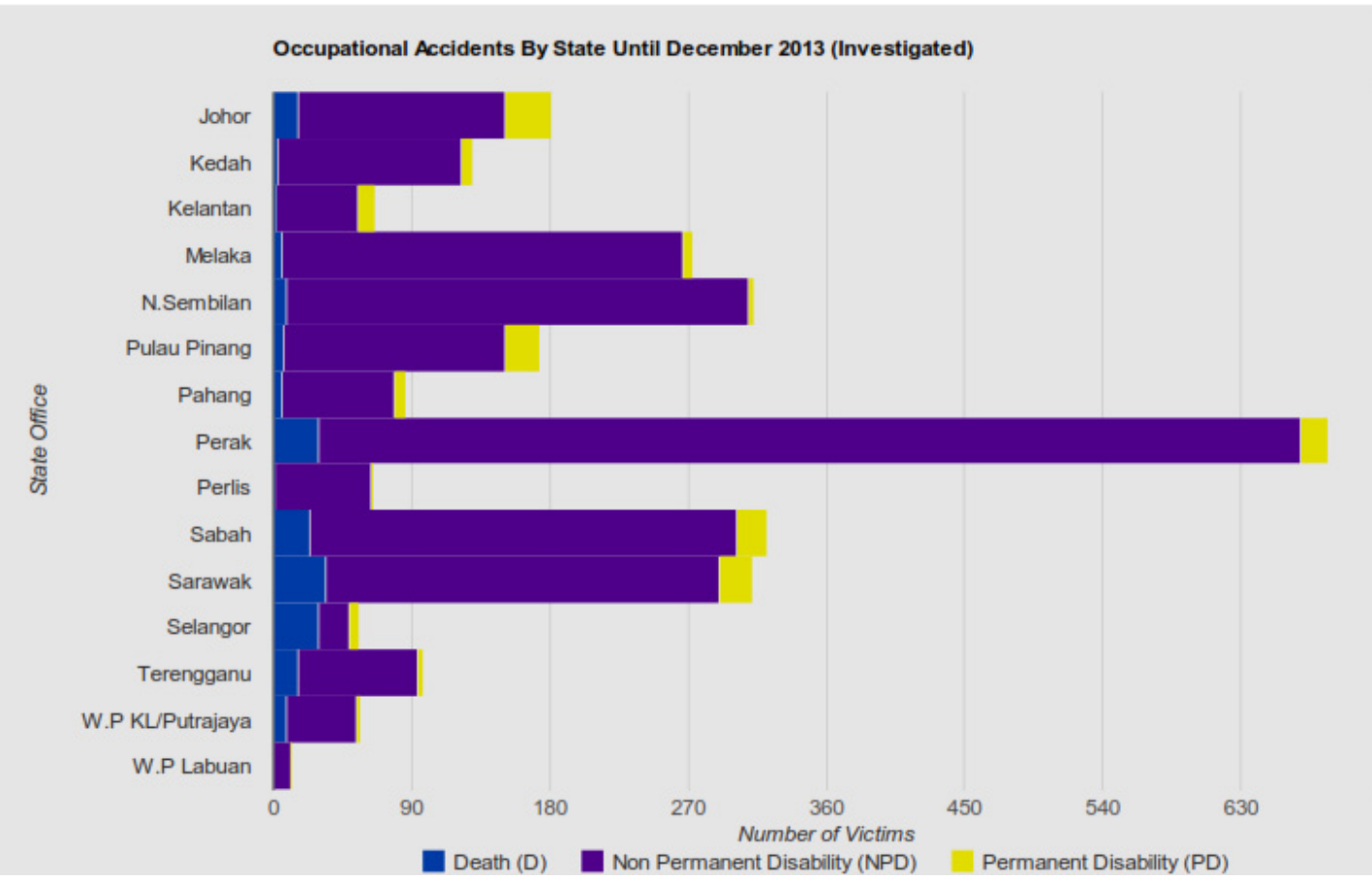

Figure 2: Occupational accidents by state until 2013 [6] 


\section{Research Methodology}

The data that was collected was derived from various sources. There were two mains sources of data which were primary and secondary data. The primary data was collected from formal interviews and visual inspections. Meanwhile, the secondary data was collected from a review of literature which included previous research from published journals, theses and books. Some of the information was gathered directly from the guidelines from the Department of Safety and Health (DOSH) and the Construction Industry Development Board (CIDB) as well as the United States Government Accountability Office. The data types for the research were as follows:

i. Primary data: Semi-structured interviews and visual inspections - The personnel that were interviewed were selected among safety officers, safety site supervisors and managers at the construction site.

ii. Secondary data: A literature review based on published research, journals, articles and other resources available which were relevant to the research topic.

\section{Results and Discussion}

\subsection{Distribution Method}

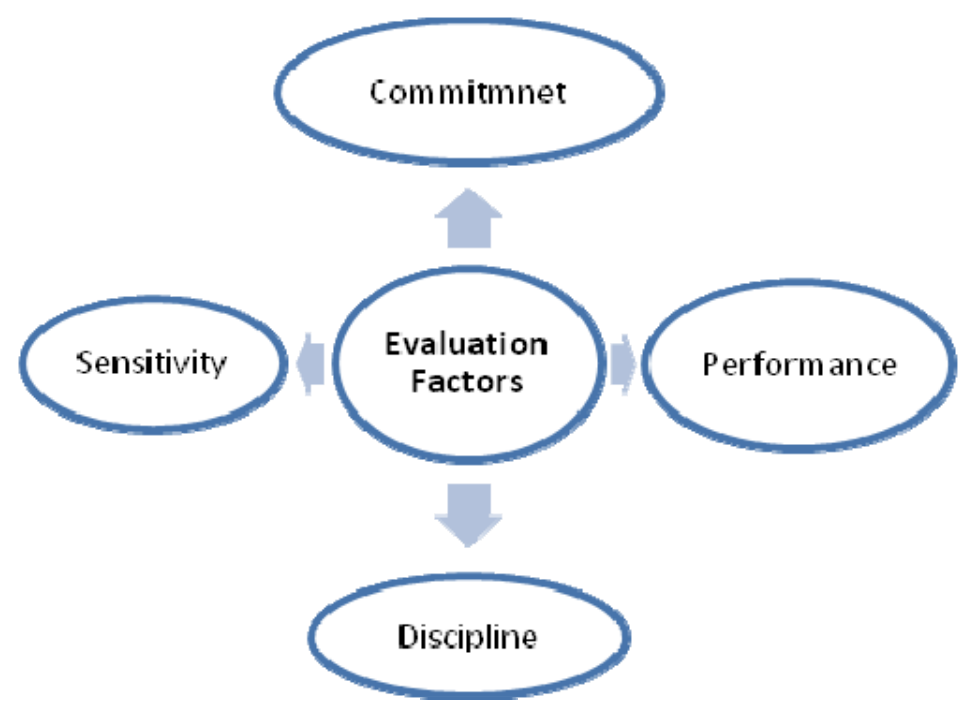

Figure 3: Evaluation factors

Based on a review of relevant literature, there are 10 categories of incentives that can be given to employees to improve their on-site safety performance. These categories include: recognition, time off, stock ownership, special assignments, advancement, increased autonomy, training and education, social gatherings, prizes, and money. The incentive value and distribution method depends on the decision of the management. According to interviewee A, their company provided an allocation for a safety programme which included any activities relating to safety, including the safety incentive programme. The allocation depended on the managers of the company and was based on their profit margin. Basically, a larger company will allocate more money or budget for an incentive programme. This statement corresponds to the response from interviewee $\mathrm{C}$, a project manager who started the programme at his current construction site by allocating money from his own pockets. This situation shows that incentive programmes can actually be top managers' driving force to improve safety on construction sites. According to interviewee D, incentives are distributed by the top managers to the 
workers. However this evaluation was based on an inspection conducted by the site supervisor and not the top managers themselves.

Figure 3 shows the evaluation factors used when giving away incentives. Most of the practitioners interviewed claimed that they distribute incentives during toolbox meetings and company occasions. The only group targeted for incentives was the workers with all the top managers evaluating their performance according to their own standards and criteria. Some of the interviewees reported that their company used a grading system to evaluate workers' performance. In these cases, numerous evaluation criteria were taken into consideration to evaluate the workers' performance. Some stated the criteria as the level of workers' commitment and sensitivity towards safety issues. Other criteria included attendance and behaviour or discipline of the workers at the construction site. According to interviewee $\mathrm{D}$, incentives or awards were given based on two categories which were "most contributions" and "the best contributor."

\subsection{Contributing Factors}

There are a few factors that can contribute to the success of the programme (Figure 4). An incentive programme is mainly purposed to motivate the workers in terms of factors relating to worksite safety. It not only focuses on the workers or employees themselves, but has a deeper goal of effectively adhering to the company's policies and initiatives to improve overall worksite safety. The following six main contributing factors of incentive programmes were listed: incentive distribution method, safety training, time period for the incentive, management awareness, workers' willingness, and type of incentive. All of these six factors are interrelated with each other.

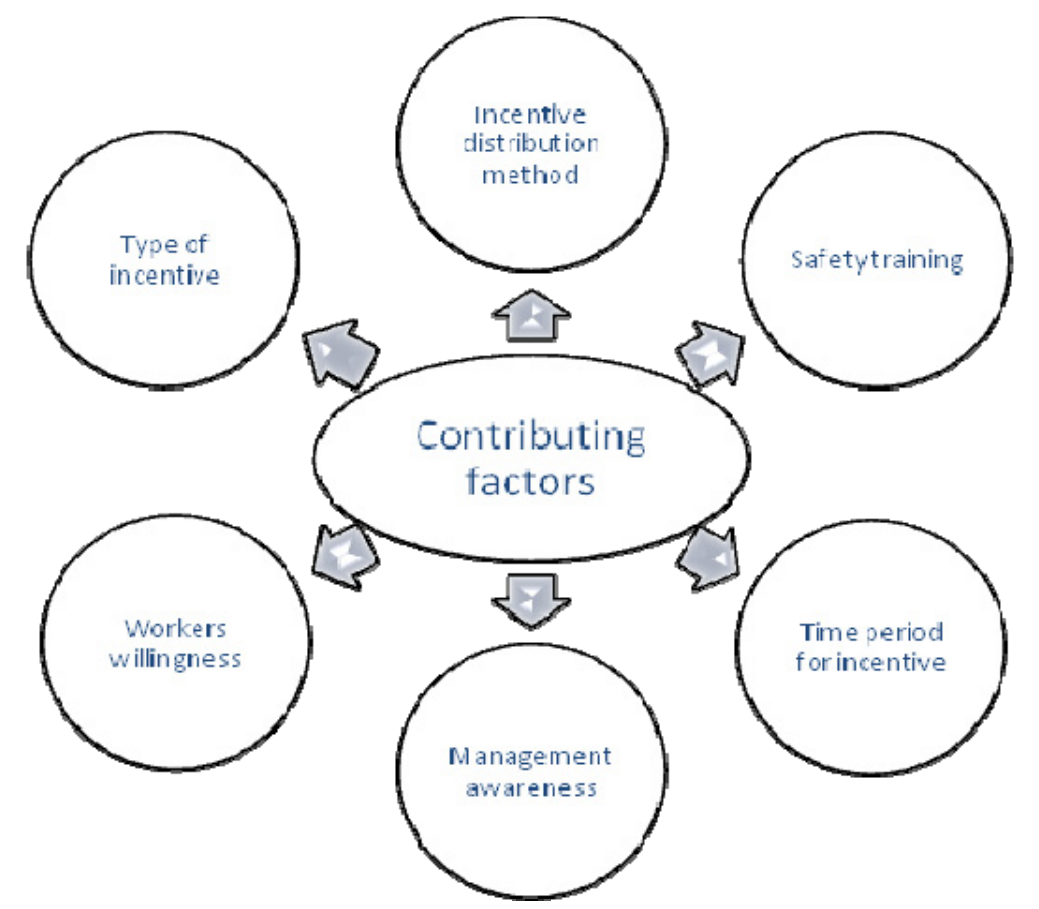

Figure 4: Contributing factors to the success of a safety incentive programme

Incentives are more effective if their distribution is separate from normal compensation. It will also be more effective if the incentive is distributed directly by the safety director or manager during special occasions or toolbox meetings. This is because managers and safety directors are those who can best influence workers regarding safety practices. The programme should be supported by safety training that involves all of the workers in order to improve their awareness of site safety practices and 
to help the workers achieve the safety policy goals of the company. Another factor is the time period in which it takes to receive the incentive. The duration between one incentive and another can also contribute to the success of the programme. Workers will be more excited to take part if the programme is conducted rarely. As such, they will be eager to improve their safety practices while waiting for the incentive receiver to be announced.

Managers are the greatest factor contributing to the success of the programme. They themselves should be aware of and adhere to safety procedures before requesting workers to do so. They are the workers' leaders so they should set a good example and show the workers the right attitude on the worksite. Managers should not be stingy in terms of giving out or allocating money for the safety programme as it will encourage the workers to work safely and reduce the number of accidents on the construction site. Hosting events which involve the workers and the award granting committee can actually help workers build self-motivation to work in a safe manner and to avoid accidents. Workers' willingness is one of the most important factors that determines the success of the programme. Essentially, the programme is not going to succeed if those being targeted are not willing to take part. One other important factor that contributes to the success of the programme is the method of distribution, whether it is a monetary or non-monetary incentive. Non-monetary incentives, in terms of awards and recognition, were found to be more effective in comparison to monetary incentives.

\subsection{Effect of Incentives}

Based on interviews with those involved in the construction industry, all of them agreed that incentives help to motivate the workers to work with safe behaviour and to increase safety awareness among the workers on construction sites. This was evident during on-site observations of projects where the worksite was more manageable and neat while workers were alert about safety procedures.

\subsection{Loss of Appreciation Value}

Appreciation of safety values is one thing on paper while on the job site, managers or clients typically just want to see the quantitative results instead of qualitative value. In other words, they will cut corners on safety to get the greatest profit. Instead, the same minor hazards tend to occur repeatedly or sometimes, ACT, UCUA, STOP CARDs or anything similar to a complaint card are overused. A complaint card is a card that is purposely used for minor cases on work sites. It is more profitable for everyone if workers can be rewarded and given incentives for being sensitive to safety issues. As a result, workers will feel appreciated as they receive their awards while management will also get good figures in terms of hazard reporting. Therefore, safety incentive programmes require participation and contributions from all personnel involved.

\subsection{Safety Awareness}

Incentive programmes help to improve safety awareness among workers in the construction industry. By having an incentive programme, workers can be made aware of the safety practices and policies at toolbox meetings. By introducing the incentive programme at toolbox meetings, more workers will be enticed to adopt proper safety practices at their worksite.

\subsection{Reduce Recordable Accidents}

An incentive programme also helps to reduce the number of recordable accidents on construction sites. Once workers are aware of site safety practices and all the regulations related to site safety, recordable accidents can be minimized. One criterion to receive the safety incentive programme is to have few reports of accidents or Loss Time Injury (LTI), which is part of the injuryillness based programme. For this reason, workers are eager to adapt to safety practices on their worksites. 


\subsection{Change Workers Behaviour to Adopt Safe Practices}

As incentives are introduced to workers on construction sites, they will begin to be more mindful of the potential awards and recognition, thereby taking on a new perception of the safety programme. They will become more interested in adopting safe work behaviour and avoiding hazards at the worksite in hopes of benefiting from the programme. At the same time, the worksite itself will benefit from experiencing a better safety performance.

\subsection{Minimizing Losses}

When workers are aware of and able to adapt their behaviour to conform to safety standards on construction sites, the number of losses in terms of resources can also be minimized. This happens when the safety incentives are well developed and managed well within the company.

\section{Conclusion}

In conclusion, offering rewards or other incentives, no matter the value, is an important part of improving overall safety on construction sites. Workers will feel appreciated as they receive the awards or recognition while management will also receive good ratings for better safety performance. Therefore, safety incentive programmes require participation and contributions from all personnel involved with work on construction sites.

\section{References}

1. Hasan, A. and Jha, K. (2013). "Safety incentive and penalty provisions in Indian construction projects and their impact on safety performance." International Journal of Injury Control and Safety Promotion, 20(1), 3-12. Online publication date: 1-Mar-2013.

2. Master Plan for Occupational Safety and Health in Construction Industry 2005-2010.

3. Stukhart, G. 1984. Contractual incentives. Journal of Construction Engineering and Management, ASCE, 110(1): 34-42. doi:10.1061/(ASCE)0733-9364(1984)110:1(34)

4. Hinze, J. 2002. Safety incentives: Do they reduce injuries?. Practice Periodical on Structural Design and Construction, ASCE, . 7 (2): 81-84

5. Teo, E.A.L., Ling, F.Y.Y. and Chong, A.F.W. 2005. Framework for project managers to manage construction safety.International Journal of Project Management, 23: 329-341.

6. Master Plan for Occupational Safety and Health in Construction Industry 2005-2010. 